\title{
Detección Inmunohistoquímica del Receptor de Estrógeno en el Endometrio de Ovejas de Alta Prolificidad y de Prolificidad Estándar
}

\author{
Immunohistochemical Detection of Estrogen Receptor in the \\ Endometriumof Sheep High Prolificacy and Standard Prolificacy
}

"Adriana Vasconcellos C. \& ** Marco Paredes H.

VASCONCELLOS, C.A. \& PAREDES, H. M. Detección inmunohistoquímica del receptor de estrógeno en el endometrio de ovejas de alta prolificidad y de prolificidad estándar. Int. J. Morphol., 30(3):1090-1093, 2012.

RESUMEN: Uno de los factores que incide en la capacidad reproductiva de los ovinos es la presencia de receptores de estrógeno en el tracto genital, donde regulan la expresión de numerosos genes comprometidos en su desarrollo morfológico y funcional. Posiblemente el desempeño reproductivo de diferentes razas de ovejas podría estar determinado por la expresión diferencial de estos receptores. En el presente estudio, se evaluó comparativamente el nivel de expresión del receptor de estrógeno en tejido endometrial de ovejas prepúberes de alta prolificidad (raza Texel) y de prolificidad estándar (raza Araucana) mediante análisis inmunohistoquímico. Se concluye que el nivel de expresión del receptor de estrógeno en tejido estromal, epitelial, de revestimiento y glandular del endometrio de ovejas de raza Texel es significativamente mayor que en ovejas de raza Araucana. Esta diferencia en el nivel de expresión de estos receptores podría estar relacionado con la diferencia de prolificidad entre estas razas.

PALABRAS CLAVE: Ovejas; Endometrio; Receptor estrógeno; Texel; Araucana.

\section{INTRODUCCIÓN}

Las hormonas sexuales son moduladores de la reproducción animal, ellas a través de sus receptores inducen cambios morfológicos y funcionales en el endometrio durante sus distintas etapas de desarrollo (Cherny, 1991; Meikle et al., 2001; Spencer \& Bazer, 1995). Dado que la reproducción es un fenómeno complejo debemos recordar el que cada especie animal y sus diferentes razas presentan características propias. Se ha observado que los niveles de expresión de los receptores hormonales muestran variaciones entre las distintas especie (Cunningham, 1998; Priedkkalns, 1993; Meikle et al., 2004). En ovinos los estrógenos actúan a nivel del aparato reproductor de la hembra e inducen cambios en el útero durante el periodo fetal, neonatal (Wiley et al., 1987) y durante sus fases reproductivas (Meikle et al., 1997, 2001, 2004; Vasconcellos et al., 2009a, 2009b). Varios son los factores que intervienen en la morfogénesis uterina: factores hormonales, celulares y mecanismos moleculares aún no definidos. Los factores endocrinos actuarían en forma dinámica en la morfogénesis y citodiferenciación del endometrio (Carpenter et al., 2003; Priedkkalns, 1993).
Sin embargo lo que gatilla estos cambios es la activación de los receptores de estrógeno alfa con lo cual se inicia la proliferación glandular endometrial en la oveja neonata (Carpenter et al., 2003 y 2004). Posteriormente las glándulas endometriales ya desarrolladas van a sintetizar, secretar y transportar sustancias que son necesarias para la posterior implantación y crecimiento embrio-fetal (Gray et al., 2002).

El endometrio de las ovejas presenta una característica que lo diferencia de otros mamíferos (Meikle et al., 2004; Vasconcellos et al., 2009a), y es la presencia de receptores de estrógenos y progesterona fisiológicamente activos en la etapa prepuberal (Garófalo \& Tasende, 1996; Meikle et al., 2001), no habiéndose encontrado aún una explicación del significado fisiológico de esta expresión de receptores en ovejas jóvenes. Encontramos pocos estudios en los cuales se hayan analizado variaciones en la expresión molecular de los receptores de estrógeno en razas distintas, por lo tanto elevados índices de fertilidad y alta tasa de gestación

* Departamento de Ciencias Básicas Facultad de Medicina, Universidad de La Frontera, Temuco, Chile. CEBIOR (Centro Biotecnológico de la Reproducción), Universidad de La Frontera, Temuco, Chile.

${ }^{* * *}$ Laboratorio de Investigación en Biotecnología Animal; Departamento de Ciencias Básicas Facultad de Medicina, Universidad de La Frontera, Temuco, Chile. Doctorado en Ciencias Morfológicas, Universidad de La Frontera, Temuco, Chile. 
múltiple podría relacionarse con una mayor expresión de receptores endometriales en la oveja.

De este modo, el objetivo fue evaluar la expresión inmunohistoquímica del receptor de estrógeno en el endometrio de ovejas prepúberes de dos razas distintas, una de alta fertilidad (Texel) y otra de fertilidad estándar (Araucana).

\section{MATERIAL Y MÉTODO}

Animales. Se utilizaron ocho ovejas prepúberes de dos años de edad; cuatro de raza Texel y cuatro de raza Araucana. Los animales fueron mantenidos en el Campo Experimental Maquehue de la Universidad de La Frontera (Región de La Araucanía), Chile hasta el sacrificio. El manejo de los animales se realizo de acuerdo con el consentimiento del Comité de Ética de la Facultad de Medicina de La Universidad de La Frontera.

Luego del sacrificio, se extrajo el útero el cual fue dividido quirúrgicamente en tres partes: cervix, cuerpo y cuernos. Cada una de las secciones se fijaron en parafolmaldehido al $10 \%$. Para el análisis del tejido endometrial se utilizaron los cuernos uterinos.

Análisis inmunohistoquímico. Las muestras fijadas se incluyeron en Paraplast (Merck, Alemania) y posteriormente se prepararon cortes de 5 micras a partir del tejido incluido. Los cortes se procesaron eliminado el Paraplast dos veces con Xilol por 20 min cada vez. Luego, los cortes desparafinados, se hidrataron mediante incubación en una batería de concentración decreciente de etanol (100 a 50\%) y tres incubaciones con tampón fosfato salino (PBS) por 5 minutos cada vez. Posteriormente, se eliminó la actividad de peroxidasas endógenas incubando con $\mathrm{H}_{2} \mathrm{O}_{2}$ al $3 \%$ en metanol por 10 minutos. Se lavó luego, dos veces con PBS por 5 minutos cada vez y se procedió a incubar los cortes en solución de bloqueo (BSA 1\% y tritón 100X 0,3\%, diluidos en PBS) a temperatura ambiente por 30 minutos. Los cortes se incubaron a continuación con un anticuerpo policlonal anti-RE (H-184; Santa Cruz Biotechnology, USA) diluido 1:1000 en solución de bloqueo durante 12 horas a $37^{\circ} \mathrm{C}$. Posteriormente los cortes se lavaron 3 veces con PBS por 5 minutos cada vez. En adelante se utilizó el sistema de detección LSABTM Kits (Dako, USA) el cual se basa en el reconocimiento del primer anticuerpo por un segundo anticuerpo anti-IgG conjugado a biotina el cual interacciona específicamente con el complejo estreptoavidina conjugada a peroxidasa. Los lavados y tiempos de incubación se efectuaron de acuerdo a las instrucciones del fabricante del kit.
El revelado se realizó incubando con diaminobencidina $(0,5 \%)$ y perhidrol $(1 \%)$ en PBS, a temperatura ambiente por 5 a $10 \mathrm{~min}$. Los cortes histológicos ya procesados, se lavaron con agua destilada y seguidamente se tiñó para contraste nuclear con hematoxilina. Luego, los cortes se deshidrataron en una batería creciente de etanol y se diafanizó con xilol. Finalmente los cortes se montaron con resina Entellan (Merck). El análisis microscópico y captura de imágenes digitales se efectuó utilizando un microscopio Leitz, Laborlux 12.

\section{RESULTADOS}

El análisis inmunohistoquímico del endometrio de ovejas prepúberes indica expresión del receptor en zonas carunculares y áreas intercarunculares-glandulares de ambas raza, sin embargo se aprecia claramente que las señales inmunorreactivas nucleares son de mayor intensidad en ovejas de raza Texel. También se puede destacar que aparentemente, el número de células inmunoreactivas también es mayor en estroma y epitelio glandular de ovejas Texel (Fig. 1).

\section{DISCUSIÓN}

En diferentes razas varía el comportamiento reproductivo de los ovinos, y dentro de los factores que inciden en la capacidad reproductiva, se encuentra la expresión y distribución de receptores de estrógenos en su tracto genital. Se sabe que la respuesta reproductiva a nivel celular depende de múltiples factores, entre ellos el número y afinidad de los receptores hormonales en los tejidos del sistema reproductor, el estadio reproductivo en el que se encuentre la hembra, factores ambientales, entre otros (Meikle et al., 2004). La expresión del receptor de estrógeno en animales prepúberes se ha detectado anteriormente en ovejas de la raza Corriedale (Garófalo \& Tasende), Romney Marsh (Meikle et al., 1997, 2004; Vasconcellos et al., 2005) y en raza Araucana (Vasconcellos et al., 2009a, 2009b, 2010). A diferencia de otros mamíferos, como en canidos, donde no es posible evidenciar receptores de estrógenos en la etapa prepuberal (Vasconcellos et al., 2006), en las ovejas la expresión de estos receptores es evidenciable, encontrándose en estado fisiológicamente activos. En ovinos se han descrito receptores de estrógeno en sus dos isoformas: alfa y beta y se sostiene que el primero es el receptor proteico que media la clásica acción estrogénica en el tracto reproductivo aunque se han identificado también receptores estrogénicos de la isoforma beta en útero y principalmente en ovarios (Ing \& Ott, 1999). 

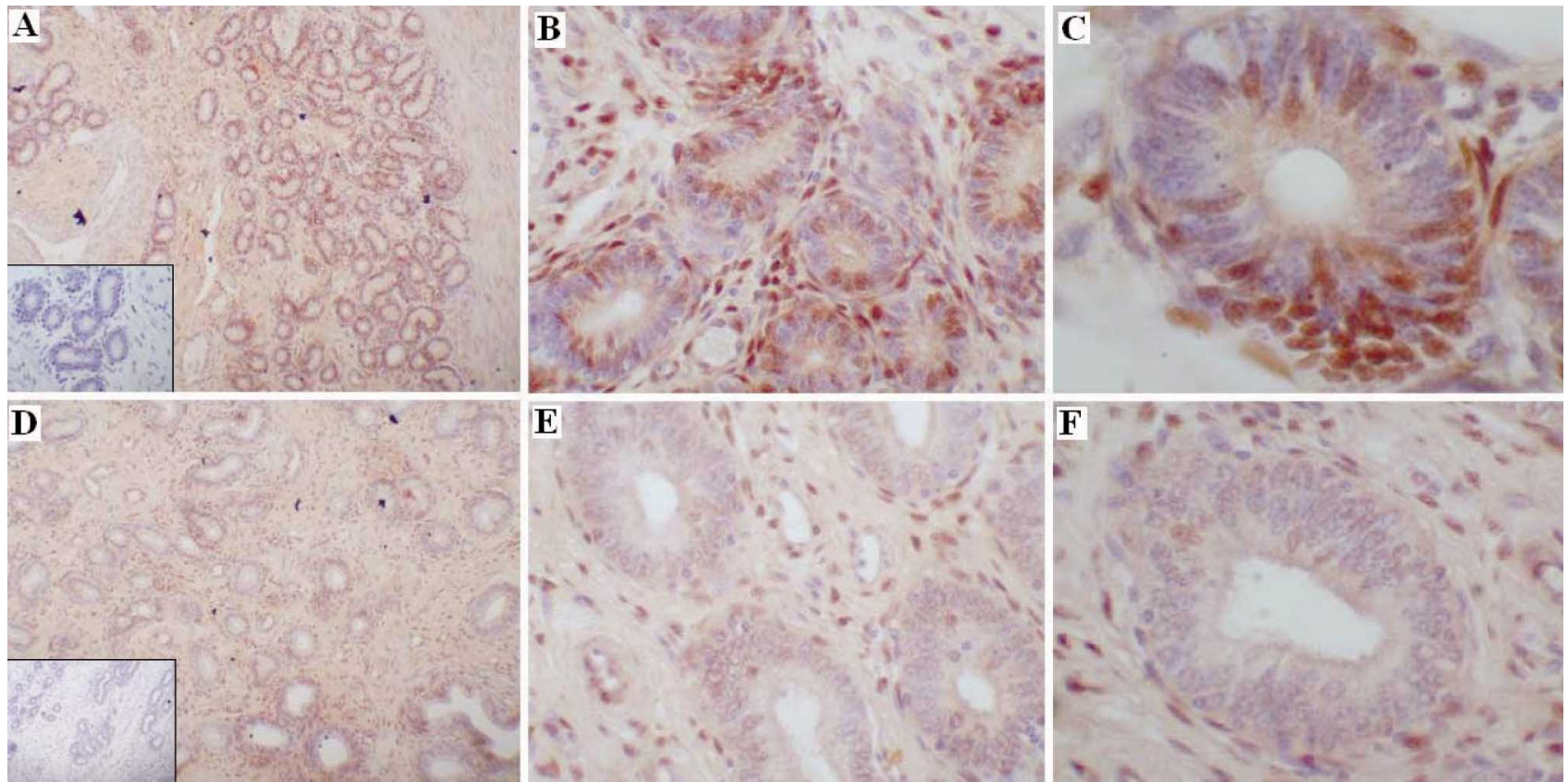

Fig. 1. Expresión inmunohistoquímica del receptor de estrógeno alfa en endometrio de ovejas de raza Texel (A, B y C) y Araucana (D, E y F). Recuadro A y D (100 X), B y E (400X), C y F (1000X). Recuadros inferiores en A y D son controles negativos. Se muestra la imagen más representativa del análisis efectuado en ocho animales.

Nuestro estudio realizado con receptores estrogénicos alfa indica que la expresión inmunohistoquímica del receptor de estrógeno en tejido estromal y epitelial del endometrio de ovejas de raza Texel es de mayor intensidad que en ovejas de raza Araucana y esta diferencia de nivel de la expresión de estos receptores podría eventualmente explicar las diferencias en la capacidad reproductiva entre razas de alta prolificidad como texel y de prolificidad estándar como Araucana. Evidentemente la capacidad reproductiva de estos animales no solo depende del nivel expresión del gen del receptor de estrógeno, siendo necesarios muchos otros factores moleculares que modulan en conjunto la condición reproductiva de las hembras, sin embargo por su papel inductor de desarrollo endometrial es interesante evaluar a futuro el significado preciso de el nivel de expresión del receptor de estrógeno y la prolificidad en estos animales.

\section{AGRADECIMIENTOS}

Se agradece a la Dirección de Investigación de la Universidad de La Frontera por el apoyo económico entregado mediante el Proyecto DIUFRO 12-0027.

VASCONCELLOS, C. A. \& PAREDES, H. M. Immunohistochemical detection of estrogen receptor in the endometrium of sheep high prolificacy and standard prolificacy. Int. J. Morphol., 30(3):1090-1093, 2012.

SUMMARY: A factor that affects the reproductive capacity of sheep is the presence of estrogen receptors in the genital tract, where they regulate the expression of numerous genes involved in morphological and functional development. Possibly the reproductive performance of different breeds of sheep could be determined by the differential expression of these receptors. In the present study, we evaluated comparatively level of estrogen receptor expression in endometrial tissue ewe lambs high prolificacy (Texel) and standard prolificacy (Araucana) by immunohistochemical analysis. It is concluded that the level of estrogen receptor expression in stromal tissue, epithelial lining and endometrial glandular Texel Sheep is of greater intensity than in ewes Araucana, this difference in the expression level of these receptors could be related to the increased prolificacy of Texel breed.

KEY WORDS: Sheep; Endometrium; Estrogen receptor; Texel; Araucana; Breeds. 


\section{REFERENCIAS BIBLIOGRÁFICAS}

Carpenter, K.D; Hayaski, K. \& Spencer, T.E. Ovarian regulation of endometrial gland morphogenesis and activin-follistatin system in the neonatal ovine uterus. Biol. Reprod., 69(3):85160, 2003.

Cherny, R. A. Inmunohistochemical localization of estrogen receptors in the endometrium of the ewe. Reprod. Fertil. Dev., 3:321-31, 1991.

Cunningham, J. Ciclos reproductivos en Fisiología Veterinaria. México DF, Interamericana McGraw-Hill, 1998. pp.494502.

Garófalo, E. G. \& Tasende, C. Uterine estrogen and progesterone receptors in prepubertal ewes: distribution in myometrium, endometrium and caruncles. Vet. Res., 27(2):177-3, 1996.

Gray, C. A.; Burghardt, R. C.; Johnson, G. A.; Bazer, F. W. \& Spencer, T. E. Evidence that absence of endometrial gland secretions in uterine gland knockout ewes compromises conceptus survival and elongation. Reproduction, 124(2):289-300, 2002.

Ing, N. H. \& Ott, T. L. Estradiol up-regulates estrogen receptoralpha messenger ribonucleic acid in sheep endometrium by increasing its stability. Biol. Reprod., 60(1):134-9, 1999.

Meikle, A.; Garófalo, E. G.; Rodríguez-Piñón, M.; Tasende, C. \& Sahlin, L. Regulation by gonadal steroids of estrogen and progesterone receptors along the reproductive tract in female lambs. Acta Vet. Scand., 42(1):161-9, 2001.

Meikle, A.; Tasende, C.; Rodríguez, M. \& Garófalo, E. G. Effects of estradiol and progesterone on the reproductive tract and on uterine sex steroid receptors in female lambs. Theriogenology, 48(7):1105-13, 1997.

Meikle, A.; Tasende, C.; Sosa, C. \& Garófalo, E. G. The role of sex steroid receptors in sheep female reproductive physiology. Reprod. Fertil. Dev., 16(4):385-94, 2004.

Priedkkalns, J. Sistema reproductor femenino. En: Dellmann, D. Histología Veterinaria. $2^{a}$ Ed. Zaragoza, Acribia S.A., 1993. pp.279-83.

Spencer, T. E. \& Bazer, F. W. Temporal and spatial alterations in uterine estrogen receptor and progesterone receptor gene expression during the estrous cycle and early pregnancy in the ewe. Biol. Reprod., 53(6):1527-43, 1995.

Vasconcellos, A.; Sepulveda, N.; Castillo, J. \& Rosas, C. Presencia de receptores de Estrógeno y de Progesterona en el Endometrio de ovejas Prepúberes. Estudio inmunocitoquímico. Int. J. Morphol., 23(4):393-6, 2005.
Vasconcellos C. A.; Sepúlveda B. N. \& Pacheco C. C. Presencia de receptores de estrógeno, progesterona y de $\mathrm{CBG}$ en el tracto genital de ovejas y de perras. Estudio inmmunocitoquímico. Int. J. Morphol., 24(3):457-62, 2006.

Vasconcellos, A.; Paredes, M.; Carrasco, J. \& Núñez, D. Analysis of the Expression of Estrogen and Progesterone Receptors in the Endometrium of Ewes of the Races Romney Marsh and Araucana. Int. J. Morphol., 27(1):97-100, 2009a.

Vasconcellos, A.; Paredes M.; Núñez D.; Barrientos, E.; Olmazabal, Y.; Navarrete, J. \& Molina, B. Analysis of the Expression of Estrogen Receptors in the Endometrium of Ewes Fed with Normal and Supplementary Diet. Int. J. Morphol., 27(4):10938, 2009b.

Vasconcellos, C. A.; Paredes, H. M.; Núñez, R. D.; Barrientos, V. E.; Olmazábal, S. Y. \& Navarrete, V. J. Study of the Expression of Progesterone Receptors in the Endometrium of Ewes with Normal and Supplementary Diet. Int. J. Morphol., 28(2):575$8,2010$.

Wiley, A. A.; Bartol, F. F. \& Barron, D. H. Histogenesis of the ovine uterus. J. Anim. Sci., 64(4):1262-9, 1987.

\author{
Dirección para correspondencia: \\ Adriana Vasconcellos C. \\ Departamento de Ciencias Básicas \\ Facultad de Medicina \\ CEBIOR, Centro Biotecnológico de la Reproducción \\ Universidad de La Frontera \\ Temuco \\ CHILE
}

Email: avascon@ufro.cl

Recibido : 22-06-2012

Aceptado: 27-07-2012 